\title{
THE COMPARISON AND EVALUATION OF CARRYING ANGLE OF ELBOW WITH ANTHROPOMETRIC MEASUREMENTS IN BOTH SEXES
}

\author{
Shahin Kazi ${ }^{1}$, Harsha A Keche ${ }^{* 2}$, Prema K Joshi ${ }^{3}$, Anjali N Wanjari ${ }^{4}$. \\ ${ }^{1}$ Associate Professor, Department of Anatomy, A.C.P.M. Medical College, Dhule, Maharashtra, \\ India.
}

${ }^{* 2}$ Associate Professor, Department of Anatomy, A.C.P.M. Medical College, Dhule, Maharashtra, India.

${ }^{3}$ Associate Professor, Department of Physiology, A.C.P.M. Medical College, Dhule, Maharashtra, India.

${ }^{4}$ Professor, Department of Anatomy, A.C.P.M. Medical College, Dhule, Maharashtra, India.

\section{ABSTRACT}

Background: The carrying angle is defined as the acute angle made by the median axis of the arm with the fully extended and supinated forearm. It is important in walking, swinging and carrying objects. Various studies have been done on the cause of the formation of carrying angle. Variations in carrying angle have been reported with age groups, gender and race but little attention has been given to correlate the carrying angle with various anthropological parameters. Hence this study was done to co-relate the carrying angle with various anthropological parameters.

Material and Methods: The present cross sectional observational study was done on 226 students (122 males and 94 females) of age group 17-21 years. A written informed consent was taken. Ethical clearance was taken from institutional ethical committee. The carrying angle of the elbow was measured by goniometer. Height was measured using a stature meter. Arm and forearm length was measured using vernier caliper. Data was statistically analyzed by "paired- $t$ " test to compare parameters in between paired observations and "unpaired- $t$ " test to compare groups. The relation between the continuous variables was found by pearson 'correlation ( $r$ ) test.

Results: Carrying angle, arm length and forearm length of right side was statistically significantly increased as compared to left side in both males and females. Right hand carrying angle showed no correlation with arm length, forearm length and height in females whereas left hand carrying angle of females and both side carrying angle of males showed negative correlation with arm length, forearm length and height.

Conclusion: Carrying angle was greater in females than males. The carrying angle was more on the right side than the left side in both sex. Carrying angle showed negative correlation with height and forearm length in both sex.

KEY WORDS: Arm length, Carrying angle, Elbow, Forearm length, Height, Sex.

Address for Correspondence: Dr. Harsha A Keche, Associate Professor, Department of Anatomy, A.C.P.M. Medical College, Dhule, Maharashtra, India. E-Mail: drharshakeche@rediffmail.com

\begin{tabular}{|c|c|c|}
\hline \multicolumn{3}{|c|}{ Access this Article online } \\
\hline \multirow{2}{*}{$\begin{array}{l}\text { Quick Response code } \\
\text { DoI: } 10.16965 / \text { ijar.2017.443 }\end{array}$} & \multicolumn{2}{|c|}{$\begin{array}{l}\text { Web site: International Journal of Anatomy and Research } \\
\text { ISSN 2321-4287 } \\
\text { www.ijmhr.org/ijar.htm }\end{array}$} \\
\hline & $\begin{array}{l}\text { Received: } 07 \text { Sep } 2017 \\
\text { Peer Review: } 08 \text { Sep } 2017 \\
\text { Revised: None }\end{array}$ & $\begin{array}{l}\text { Accepted: } 20 \text { Oct } 2017 \\
\text { Published (O): } 01 \text { Dec } 2017 \\
\text { Published (P): } 01 \text { Dec } 2017\end{array}$ \\
\hline
\end{tabular}

\section{INTRODUCTION}

The carrying angle is defined as the acute angle made by the median axis of the arm with the median axis of the fully extended and supinated 
forearm. It measures the lateral obliquity of the forearm[1].The average carrying angle in males is about $5^{\circ}$ whereas in females it is about $10-15^{0}$ [2]. This angle is important in walking, swinging and carrying objects[2]. It permits the arm to swing without contacting the hips during walking[2].

Various studies have been done on the cause of formation of carrying angle. Some suggest that the valgus angulation of the forearm is a result of the configuration of the articulating surface of the humerus and ulna [1,2].Moreover in ulna a curved ridge is present between olecranon and coronoid process which fits the trochlear groove of humerus. The shaft of ulna is deflected by this ridge which accounts for most of the carrying angle $[3,4]$. But recent studies suggest that the medial edge of trochlea of humerus projects $6 \mathrm{~mm}$ below the lateral edge and the obliquity of the superior articular surface of the coronoid process may be responsible for the angulation [5].

Knowledge of carrying angle is important anthropologically for differentiation of sex in fragmentary remains and also to understand sexual dimorphism which is more common in bones [6]. It is important in the diagnosis of the disease of lateral and medial epicondyle [7]. It helps in the monitoring of traumatic lesions that affect the paediatric elbow [8]. Biomechanical engineers may require knowledge of the same for designing a total elbow prosthesis [9].

Developmental, aging and possibly racial influences add further to the variability of the carrying angle[6]. Most studies have focused on the cause of the formation of carrying angle. Many have reported variations in carrying angle with age groups, gender and race but little attention has been given to correlate the carrying angle with various anthropological parameters. Hence this study was done to correlate the carrying angle with various anthropometric measurements such as length of arm, length of forearm and height.

\section{MATERIALS AND METHODS}

The present cross-sectional observational study was done on 188 students ( 86 males and 82 females) of A.C.P.M Medical, Dental and Nursing college, Dhule of age group 17-21 years.
A written informed consent was taken after explaining the aim of study in detail. Ethical clearance was taken from the institutional ethical committee. The mean age of the female subjects was $18.9 \pm 0.7$ years and male subjects was $19.1 \pm 0.9$ years

Exclusion Criteria: History of fracture of arm and / or forearm bones, deformity involving upper extremity, neuropathies, history of congenital anomalies, history of endocrine disorders, athletes.

\section{Procedure:}

Carrying angle: The carrying angle of the elbow of both hands was measured using a full circle goniometer made of flexible clear plastic with $35 \mathrm{~cm}$ long arms. Bicipital groove, Biceps brachi tendon at its insertion and Palmaris longus tendon at the wrist were palpated and marked as anatomical landmarks to demarcate the median axis of arm and forearm respectively. The measurement was taken by placing the goniometer's measurement plate at the fulcrum of one elbow. The fixed arm was placed on the median axis of the upper arm, the movable arm adjusted on the median axis of forearm. The arrow on the goniometer measurement plate indicated the angle.

Arm length: The length of the arm was measured as the distance between the lateral border of Acromion and lateral border of head of Radius with forearm in pronated position using vernier caliper.

Forearm length: The length of the forearm was measured as the distance between the lateral border of the head of radius to styloid process of radius using vernier caliper.

Three consecutive readings of the above paramaters were taken and the mean was recorded.

Height: Measurement of height of students was done using a stature meter. Height was measured from vertex to heel of the individual with bare foot in anatomical position in centimeters.

The data was tabulated and statistically analysed. Comparison of mean of parameters in between paired observations was done by 'paired t' test. Comparison in between the groups was done by 'unpaired t' test. Correlation between the continuous variables was done 
by Pearson's correlation ( $r$ ) test. The statistically significance level of $p<0.05$ was considered for interpretation[10].

Fig. 1: Measurement of Carrying angle of elbow by using goniometer.

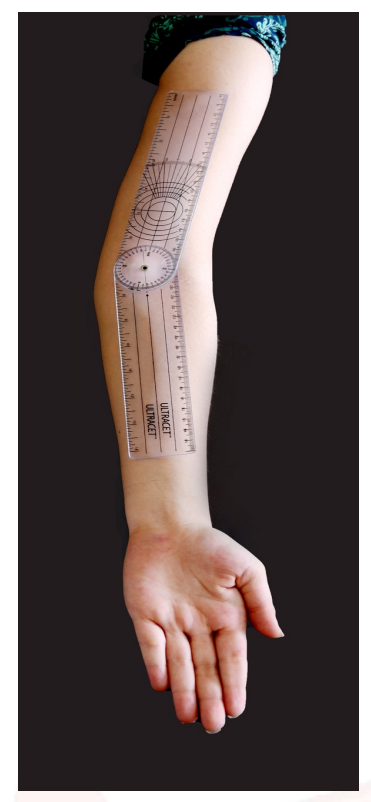

\section{RESULTS}

Table 1: Comparison of Carrying angle of elbow in males and females.

\begin{tabular}{|c|c|c|c|c|}
\hline & Female $(n=82)$ & Male $(n=86)$ & $\begin{array}{c}\text { Mean } \\
\text { difference }\end{array}$ & $p$ value \\
\hline $\begin{array}{c}\text { Right Carrying } \\
\text { angle }\end{array}$ & $11.05 \pm 2.012$ & $8.03 \pm 1.718$ & 3.014 & $<0.001$ \\
\hline $\begin{array}{c}\text { Left Carrying } \\
\text { angle }\end{array}$ & $10.26 \pm 1.858$ & $7.09 \pm 1.733$ & 3.163 & $<0.001$ \\
\hline $\begin{array}{c}\text { Mean carrying } \\
\text { angle }\end{array}$ & $10.65 \pm 1.829$ & $7.56 \pm 1.673$ & 3.088 & $<0.001$ \\
\hline
\end{tabular}

The mean carrying angle of female subjects was $10.65 \pm$ 1.829 whereas in males was $7.56 \pm 1.673$. The carrying angle of female subjects was found statistically highly significantly increased as compared to males $(P<0.001)$.

Table 2: Comparison of mean carrying angle, forearm and arm length in between two sides in both sex.

\begin{tabular}{|c|c|c|c|c|}
\hline Gender & Parameters & Right Side & Left Side & Pvalue \\
\hline \multirow{3}{*}{$\begin{array}{c}\text { Female } \\
\text { (n=82) }\end{array}$} & Carrying Angle () & $11.05 \pm 2.012$ & $10.26 \pm 1.858$ & $<0.001$ \\
\cline { 2 - 5 } & Forearm Length(cms) & $231.24 \pm 11.669$ & $228.09 \pm 11.481$ & $<0.001$ \\
\cline { 2 - 5 } & Arm Length (cms) & $280.66 \pm 13.858$ & $279.87 \pm 13.347$ & 0.435 \\
\hline \multirow{2}{*}{$\begin{array}{c}\text { Male } \\
\text { (n=86) }\end{array}$} & Carrying Angle () & $8.03 \pm 1.718$ & $7.09 \pm 1.733$ & $<0.001$ \\
\cline { 2 - 5 } & Forearm Length(cms) & $255.74 \pm 13.387$ & $252.87 \pm 12.852$ & $<0.001$ \\
\cline { 2 - 5 } & Arm Length (cms) & $311.09 \pm 17.491$ & $307.34 \pm 16.747$ & 0.007 \\
\hline
\end{tabular}

Carrying angle of the right side was statistically increased as compared to left side in both males and females. The forearm length and the arm length of right side was also found to be statistically significantly more as compared to left side in both males and females.

Table 3: Correlation of anthropometric parameters with carrying angle of elbow in females $(n=82)$.

\begin{tabular}{|c|c|c|c|c|c|c|c|c|}
\hline \multicolumn{2}{|c|}{ Carrying Angle } & \multicolumn{2}{|c|}{ Carrying angle } & \multicolumn{2}{|c|}{ Forearm length } & \multicolumn{2}{c|}{ Arm Length } & \multirow{2}{*}{ Height } \\
\cline { 2 - 9 } \multicolumn{2}{|c|}{} & Right & Left & Right & Left & Right & Left & \\
\hline \multirow{2}{*}{ Right } & $r$ & 1 & 0.786 & -0.023 & -0.086 & 0.048 & 0.168 & -0.092 \\
\cline { 2 - 9 } & $p$ value & & $<0.001$ & 0.84 & 0.441 & 0.666 & 0.131 & 0.411 \\
\hline \multirow{2}{*}{ Left } & $r$ & 0.786 & 1 & -0.177 & -0.225 & -0.068 & -0.013 & -0.151 \\
\cline { 2 - 9 } & $p$ value & $<0.001$ & & 0.112 & 0.042 & 0.541 & 0.907 & 0.175 \\
\hline
\end{tabular}

Table 3 Shows statistically highly significant $(P<0.001)$ positive correlation of carrying angle of right and left side in females. Carrying angle of right side showed no correlation with forearm length, arm length and height in females. Shows statistically highly significant $(P<0.001)$ positive correlation of carrying angle of right and left side in females. Carrying angle of right side showed no correlation with forearm length, arm length and height in females.

Table 4: Correlation of anthropometric parameters with carrying angle of elbow in males $(n=86)$.

\begin{tabular}{|c|c|c|c|c|c|c|c|c|}
\hline \multirow{2}{*}{ Carrying Angle } & \multicolumn{2}{|c|}{ Carrying angle } & \multicolumn{2}{l|}{ Forearm length } & \multicolumn{2}{c|}{ Arm Length } & \multirow{2}{*}{ Height } \\
\cline { 3 - 9 } & & Right & Left & Right & Left & Right & Left & \\
\hline \multirow{2}{*}{ Right } & $r$ & 1 & 0.88 & -0.269 & -0.236 & -0.177 & -0.053 & -0.348 \\
\cline { 2 - 8 } & $p$ value & & $<0.001$ & 0.012 & 0.028 & 0.102 & 0.63 & 0.001 \\
\hline \multirow{2}{*}{ Left } & $r$ & 0.88 & 1 & -0.301 & -0.265 & -0.17 & -0.073 & -0.328 \\
\cline { 2 - 8 } & $p$ value & $<0.001$ & & 0.005 & 0.014 & 0.119 & 0.505 & 0.002 \\
\hline
\end{tabular}

Table 4 Shows statistically highly significant $(P<0.001)$ positive correlation of carrying angle of right and left limbs in males. Right limb carrying angle showed statistically significant $(P<0.001)$ negative correlation with forearm length, arm length and arm length and height in males. Left limb carrying angle showed statistically significant $(P<0.05)$ negative correlation with forearm length, arm length and height in males.

\section{DISCUSSION}

Table 1 it was seen that the carrying angle of females was significantly more than males.This matched with the findings of Patil GV et al, Raichandani L et al, Manglaur V et al, Kumari LK et al [11-14]. The greater angle in females as compared to males is considered as a secondary sexual characteristic. As according to the study of some authors the increase is seen in females only after puberty [1,2]. Hence it can be due to hormonal influence [12]. It may be that the greater carrying angle develops in response to the broader pelvis in females to keep the forearm away from the side of the pelvis when the upper limb swings during walking [6]. But some authors contradicted this as the carrying angle is formed only when the forearm is fully supinated and extended at the elbow and during walking the forearm is pronated and elbow is slightly flexed. So the carrying angle is not present during walking [6].

According to some authors the apparent difference in gender may be due to increased joint laxity in females, permitting a greater degree 
of extension which leads to more carrying angle [8]. Moreover when the forearm is pronated the proximal part angulates. Due to this the medial part of the trochlear notch moves more away from the humeral articular surface than the lateral part. As a result the medial lip of trochlea grows more distally than the lateral lip and also the valgus tilt of the distal humeral articulation with respect to the longitudinal axis of humerus is more in females leading to more carrying angle in them [8]. Olecranon coronoid angle exhibiting high degree of sexual dimorphism may be one of the cause of sexual differences observed in carrying angle. Inferior one third of the shaft of female humerus appears to have a slight radial deviation which may cause a more carrying angle in woman [12].

Table 2 shows increased carrying angle on right side as compared to left side in both males and females. It also revealed that arm and forearm length of right side was more as compared to left side in both males and females. This matched with the findings of Rajesh $B$ et al, Manoranjitham $R$ et al $[2,6]$.

In contrast in studies done by Sharma $K$ et al and Lim $V$ et al it was seen that carrying angle of left side was more than the right side in both sex $[7,8]$.

Difference between the carrying angle of right and left sides may be due to ligamentous laxity at the medial elbow or asymmetrical bone growth [2]. The angle is greater in the dominant limb than in the non dominant limb of both sexes, suggesting that the natural forces acting on the elbow modify the carrying angle $[2,6]$.

Table 3 Carrying angle of right side shows no correlation whereas left side carrying angle shows negative correlation with forearm length ,arm length and height in females.

Table 4 Shows negative correlation of right and left side carrying angle with forearm length, arm length, height in males. Similar findings were seen in the study of Ruparelia S et al, Sharma K et al, Kumari L K et al $[1,7,14]$.

If the height of a person is less and therefore length of forearm (ulna) is lesser, then because of shorter lever arm, the proximal end has to angulate more in order to bring the hand in pronated position for routine work.Therefore in a shorter person the medial part of trochlear notch of ulna goes more away from the medial flange of trochlea which can now grow more than in a person with longer forearm leading to greater carrying angle $[6,7]$. Greater the length of the forearm bones, lesser is the angulation of proximal articular surface and therefore lesser is the carrying angle [6]. The mean height of females in this study was $154.51 \pm 5.892 \mathrm{~cm}$ and in males was $169.00 \pm 6.015$.The height of the females is less as compared to males. According to Table 1 the carrying angle of females is significantly more than males. The lesser height in females might have also contributed to greater carrying angle in them as compared to the males.

\section{CONCLUSION}

In the present study it was found that the carrying angle was significantly greater in females as compared to males. It may be due to hormonal influences or increased joint laxity in females. The increased growth of medial lip on trochlea as compared to lateral lip in females along with increased vagal tilt of distal humeral articulation with longitudinal axis of humerus also contributes for the increased carrying angle. It was also observed that the carrying angle on the right side was greater than left side which may be due to ligamentous laxity or asymmetrical bone growth. It was seen that the carrying angle in females on the right side did not show any correlation with the forearm length, arm length and height whereas the left side carrying angle in females and both sides carrying angle in males showed negative correlation with arm length, forearm length and height. Greater the height, greater is the forearm length, lesser in the angulation of proximal articulating surface and lesser is the carrying angle. Thus the value of carrying angle and its correlation with height, forearm length and sexual variation is of immense importance in the management of elbow dislocation, elbow deformities, elbow fractures and elbow reconstruction. As a deformity of carrying angle may result in non traumatic ulnar neuropathy,elbow instability, painful movement at elbow. This study can also help a forensic anthropologists to discriminate the sex of an individual from skeletal remains. 


\section{ACKNOWLEDGEMENTS}

We are extremely thankful to all the students who participated in this study for their cooperation for the success of this study.

\section{Conflicts of Interests: None}

\section{REFERENCES}

[1]. Ruparelia S, Patel S, Zalawadia A, Shah S, Patel S. Study of carrying angle and its correlation with various parameters. National Journal of Integrated Research in Medicine. 2010 july-sept;1(3):28-32.

[2]. Rajesh B, Reshma VR, Vaithilingam A, Jaene RC, Somasekhar IT. An evaluation of the carrying angle of the elbow joint in adolescents. International Journal of Medicine and Biomedical Research 2013 SeptDec;2(3):221-225.

[3]. Sinnatamby CS. Upper limb. In Last's anatomy Regional and Applied.11 $11^{\text {th }}$ edition. U.K. Elsevier Churchill Living stone;2006:p 63-66.

[4]. Decker GAG, DUPlessis DJ. The elbow.In Lee Mc Gregor's Synposis of surgical anatomy : $12^{\text {th }}$ edition. Bristol, Great Britain. John Wright and sons; 1986:454-459.

[5]. Johanson D. Pectoral girdle, shoulder region and axilla. In Gray's Anatomy- Anatomical basis of clinical practice. $40^{\text {th }}$ edition. Edited by Standring S. U.K.Elsevier Churchill Livingstone;2008:791-822 .

[6]. Manoranjitham R, Gosai SR, Arunkumar KR, Shalini $R$, Parathasarathi R. Study of carrying angle of medical students by using goniometer. Indian Journal of Basic and Applied Medical Research. 2015 june;4(3):459-466.
[7]. Sharma K. Mansur DI, Khanal K, Haque MK. Variation of carrying angle with age, sex, height and special reference to side. Kathmandu University Medicine Journal 2013;44(4):315-318.

[8]. Lim V. Jacob NA, Shahghani MF, Chi wang DL, Devi AK. An Anthropometric study on the carrying angle of elbow among young adults of various ethnicties in Malaysia. NJIRM 2014 Nov-Dec;5(6):20-23.

[9]. Bari W, Alam M, Omar S. Goniometry of elbow carrying angle : a comparative clinical study on sexual dimorphism in young males and females. International Journal of Research in Medical Sciences, 2015 Dec;3(12):3482-3484.

[10]. Mahajan BK. Methods of Biostatistics. $6^{\text {th }}$ Edition. Jaypee Brothers Publications; 2006:127-136.

[11]. Patil GV, Apoorva D, Kumar S. Carrying Angle : A morphometric Study in south Indian population. Journal of Evidence Based Medicine and Health Care, 2014 Dec;1(13):1686 - 1689.

[12]. Raichandani L, Sharma K, Kataria KS, Hemkawar J, Raichandani S, Agrawal S. Gonieomertric study of carrying angle and its correlation with various parameter in western rajasthan population. International Journal of Advanced Research and Review,2016;1(5):139-146.

[13]. Mangalur V, Karadkhelkar VP, Kshirsagar SV. Sexual dimorphism of carrying angle, International Journal of Recent Trends in Science and Technology 2015 July;15(3):476-478.

[14]. Kumari LK, Sekhar RC. A Comparative study of carrying angle between children and adult in Andhra population. IOSK Journal of Dental and Medical Sciences.2016 June;15(6):33-36.

How to cite this article:

Shahin Kazi, Harsha A Keche, Prema K Joshi, Anjali N Wanjari. THE COMPARISON AND EVALUATION OF CARRYING ANGLE OF ELBOW WITH ANTHROPOMETRIC MEASUREMENTS IN BOTH SEXES. Int J Anat Res 2017;5(4.3):4686-4690. DOI: 10.16965/ ijar.2017.443 